\title{
Thermal Insulation Properties of Epoxy/Mesoporous Carbon Composites
}

\author{
Gun-Young Heo ${ }^{1}$, Min-Kang $\mathrm{Seo}^{2}$, Sang-Yeob $\mathrm{Oh}^{2}$, Kyeong-Eun Choi ${ }^{3}$ and Soo-Jin Park ${ }^{1, \uparrow}$ \\ ${ }^{1}$ Department of Chemistry, Inha University, Incheon 402-751, Korea \\ ${ }^{2}$ Jeonju Institute of Machinery and Carbon Composites, Jeonju 561-844, Korea \\ ${ }^{3}$ Department of Practical Arts Education, Jeonju National University of Education, Jeonju 560-757, Korea \\ ‘e-mail: sjpark@inha.ac.kr \\ (Received January 18, 2011; Accepted March 12, 2011)
}

\begin{abstract}
This study aimed to investigate the influence of mesoporous carbons on the thermal insulation properties of epoxy/ mesoporous carbon composites. The mesoporous carbon (CMK-3) was prepared by conventional templating method using SBA-15. The epoxy/mesoporous carbon composites were prepared by mixing the synthesized CMK-3 with diglycidylether of bisphenol A (DGEBA). As experimental results, the curing reactivities of the DGEBA/CMK-3 composites were found to decrease with the addition of the CMK-3. Also, the thermal conductivities of DGEBA/CMK-3 composites were found to decrease with increasing CMK-3 content. This could be interpreted in terms of the slow thermal diffusion rate resulting in pore volume existing in the gaps in the interfaces between the mesoporous carbon and the DGEBA matrix.
\end{abstract}

Keywords : Mesoporous carbons, DGEBA/CMK-3 composites, Cure reactivities, Thermal conductivities, Pore volume

\section{Introduction}

Among the several thermosetting polymers, epoxy resins are excellent materials with which to make commercial applications in thermal, acoustic, electronic, aerospace, nuclear and many other potential fields [1,2]. Epoxy resins have been also used as matrix materials for composites because they have good thermal and mechanical properties. Also, epoxy resins are generally resistant to ionizing radiation and deterioration of their aromatic units [3-5].

Despite these obvious advantages, epoxy resins are the main source of damage for the structural materials in that they reduce control of thermal properties such as thermal dissipation and thermal insulation [6]. And, the problem with epoxy resins is that their heat control ability for structural performance is not good, leading to a decrease of impact or fracture toughness $[7,8]$. Therefore, epoxy/filler composites are often applied in order to overcome the problems. One of the widely used reinforcing fillers is carbon material [9-11].

Mesorporous carbon materials, known as a highly porous materials, are excellent materials in that they have high specific surface area, low density, low dielectric constant and low thermal conductivity $[12,13]$. Therefore, they have many potential applications for use as thermal, acoustic, electronic and catalytic fields, especially in thermal insulation [14-16].

Mesoporous carbon is used as a filler to prepare the epoxy/ mesoporous carbon composites. The goal of this work is to determine the effects of mesorporous carbon on the thermal properties of epoxy/mesoporous carbon. The reactivity of synthesized mesoporous carbon (CMK-3) confirmed by X- ray diffraction (XRD), and the cure behaviors of the epoxy/ CMK-3, are investigated by differential scanning calorimetery (DSC). Also the thermal stability factors of cured specimens are investigated by thermogravimetric analysis (TGA).

\section{Experimental}

\subsection{Materials}

The epoxy resin used for this study was diglycidylether of bisphenol A (DGEBA, YD-128 supplied from Kukdo Chem Co., Korea), which had an epoxide equivalent weight of $190-210 \mathrm{~g} \cdot \mathrm{eq}^{-1}$ and a density of $1.16 \mathrm{~g} \cdot \mathrm{cm}^{-3}$ at $25^{\circ} \mathrm{C}$. The 2ethyl-4-methyl imidazole purchased from Shikoku Chemical Co. (Japan) was selected as a curing agent.

All organic starting materials used for the synthesis of the CMK-3, such as $\mathrm{P} 123\left(\mathrm{PEO}_{20} \mathrm{PPO}_{70} \mathrm{PEO}_{20}\right)$, tetraethyl orthosilicate (TEOS), and sucrose $\left(\mathrm{C}_{12} \mathrm{H}_{22} \mathrm{O}_{11}\right)$ were purchased from Aldrich Chem Co. (Milwaukee, WI, USA). Other solvents were used as received and all reagents were used without further purification.

\subsection{Preparations of mesoporous carbon (CMK-3) and epoxy composites}

In a typical preparation of SBA-15, $4 \mathrm{~g}$ of the $\mathrm{P} 123$ as triblock copolymer was dissolved in $150 \mathrm{~mL}$ of $2 \mathrm{M} \mathrm{HCl}$ and stirred completely with slight heating. After this, $2.08 \mathrm{~g}$ of TEOS was added to the solution for a few minutes. The 
homogeneous solution was aged at $95-100^{\circ} \mathrm{C}$ for $24 \mathrm{~h}$. A white powder was obtained through filtration. The product was calcined at $550^{\circ} \mathrm{C}$ for $8 \mathrm{~h}$. The synthesis of CMK-3 as mesoporous carbon was performed using SBA- 15 silica as the template and sucrose as the carbon source, following the method by Sakamoto and co-workers [17].

To prepare the samples, the DGEBA were degassed in a vacuum oven at $100^{\circ} \mathrm{C}$ for $2 \mathrm{~h}$. The CMK-3 $(0.1,0.3$, and $1 \mathrm{phr})$ as the filler was added to the DGEBA with continuous stirring until a homogeneous mixture was obtained. Then, the 2-ethyl-4methyl imidazole as the curing agent was added to the homogeneous mixture. The curing step were $110^{\circ} \mathrm{C}$ for $1 \mathrm{~h}$, $140^{\circ} \mathrm{C}$ for $2 \mathrm{~h}$, and $170^{\circ} \mathrm{C}$ for $1 \mathrm{~h}$ in a convection oven.

\subsection{Measurements and characterization}

The characterization of the CMK-3 was measured by XRD. A DSC (Perkin-Elmer, model DSC 6, USA) was used for monitoring of curing behaviors of the DGEBA/CMK-3 composites between room temperature and $200^{\circ} \mathrm{C}$ using a heating rate of $10^{\circ} \mathrm{C} / \mathrm{min}$, under a nitrogen atmosphere.

The thermal stability of the DGEBA/CMK-3 was determined by TGA. All TGA analyses were performed with a NETZSCH TGA 209 at a heating rate of $10^{\circ} \mathrm{C} / \mathrm{min}$ from 30 to $850^{\circ} \mathrm{C}$ under nitrogen gas. The thermal conductivity of the DGEBA/CMK-3 composites was measured using a thermal conductivity analyzer (LFA 447, NETZSCH Instruments, Germany).

\section{Results and Discussion}

Fig. 1 shows the XRD patterns of the synthesized SBA-15 and CMK-3. As can be seen in Fig. 1, the intense peak at low angle can be attributed to the 100 reflection and the two peaks at higher angles can be attributed to the 110 and 200

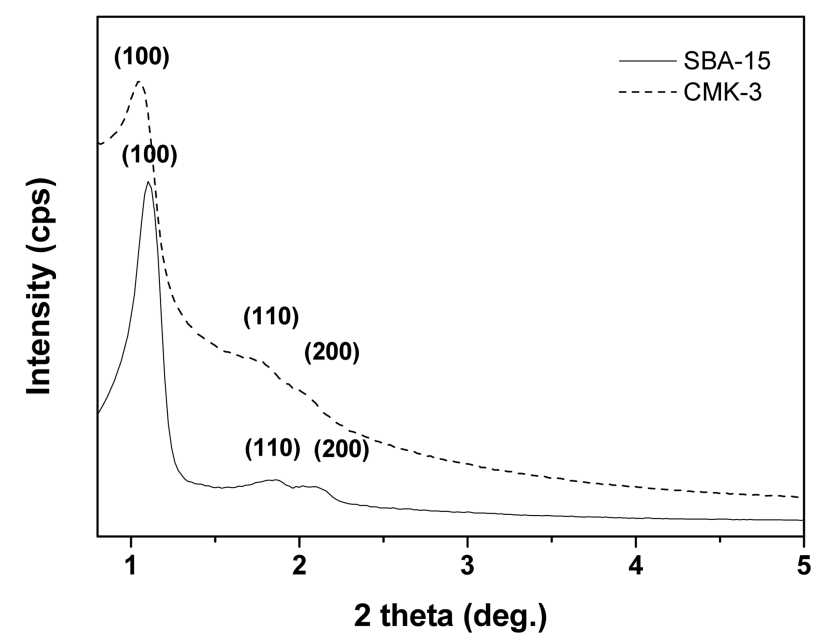

Fig. 1. X-ray diffraction patterns of the synthesized SBA-15 and mesoporous carbon (CMK-3).
Table 1. Textural Properties of the CMK-3

\begin{tabular}{lcccc}
\hline & $\mathrm{S}_{\mathrm{BET}^{\mathrm{a}}}$ & $\mathrm{V}_{\mathrm{T}}{ }^{\mathrm{b}}$ & $\mathrm{V}_{\mathrm{M}}{ }^{\mathrm{c}}$ & $\mathrm{F}_{\mathrm{M}}{ }^{\mathrm{d}}$ \\
\hline CMK-3 & 891 & 1.13 & 1.04 & 5.07 \\
\hline
\end{tabular}

CMK-3: mesoporous carbon.

${ }^{\text {a }}$ Specific surface area $\left(\mathrm{m}^{2} / \mathrm{g}\right)$.

${ }^{\mathrm{b}}$ Total pore volume $\left(\mathrm{cm}^{3} / \mathrm{g}\right)$.

${ }^{c}$ Micropore volume $\left(\mathrm{cm}^{3} / \mathrm{g}\right)$

${ }^{\mathrm{d}}$ Fraction of micropore $\left(\mathrm{cm}^{3} / \mathrm{g}\right)$.

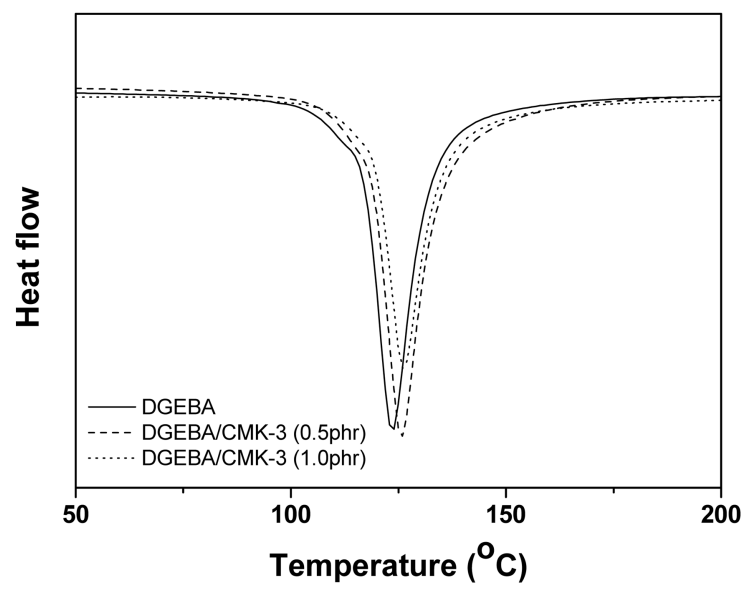

(a)

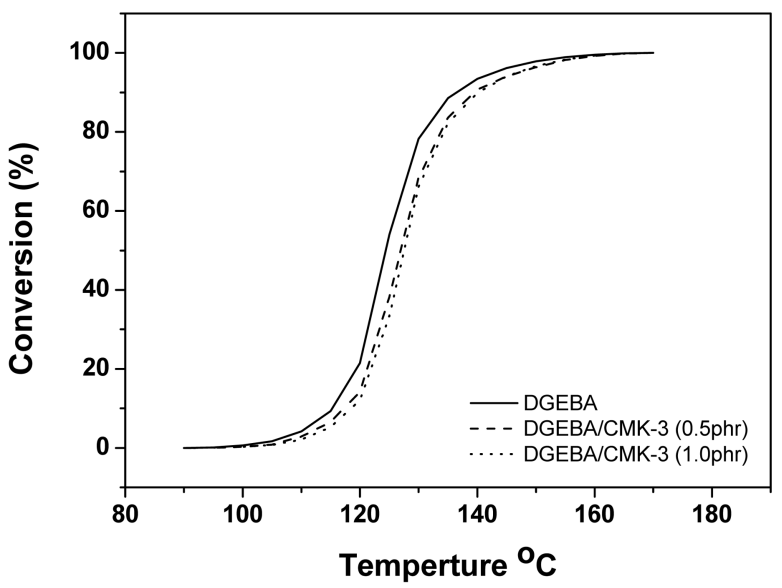

(b)

Fig. 2. (a) DSC thermograms of diglycidylether of bisphenol A (DGEBA)/ mesoporous carbon (CMK-3) composites. (b) Conversion of DGEBA/CMK-3 composites.

reflections. From these patterns, the CMK-3 gives typical XRD pattern of a 2-d hexagonal $(\mathrm{P} 6 \mathrm{~mm})$ structure. The specific surface areas of the CMK-3 were calculated by the Brunauer-Emmett-Teller (BET) method. The results are summarized in Table 1. As shown in Table 1, the specific surface areas of CMK-3 used for this study was $891 \mathrm{~m}^{2} / \mathrm{g}$. The average pore diameter of the synthesized CMK-3 is $4.3 \mathrm{~nm}$.

Fig. 2(a) shows the DSC thermograms of DGEBA/CMK-3 composites with 2-ethyl-4-methyl imidazole. As can be seen 


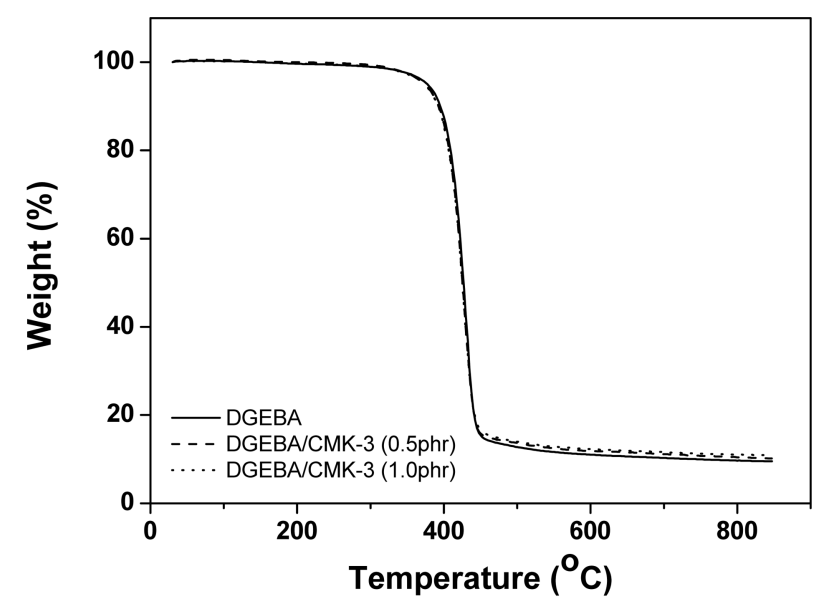

Fig. 3. Thermogravimetric analysis thermograms of diglycidylether of bisphenol A (DGEBA)/mesoporous carbon (CMK-3) composites.

in Fig. 2(a), the DSC thermograms of the DGEBA/CMK-3 systems are very similar but the initial curing temperature of DGEBA, DGEBA/CMK-3 $0.5 \mathrm{phr}$ and DGEBA/CMK-3 1.0 phr were found to be $113^{\circ} \mathrm{C}, 116^{\circ} \mathrm{C}$ and $118^{\circ} \mathrm{C}$, respectively. The main exotherm peaks of DGEBA, DGEBA/CMK-3 0.5 phr and DGEBA/CMK-3 $1.0 \mathrm{phr}$ showed maximum exotherm peaks at $123^{\circ} \mathrm{C}, 125^{\circ} \mathrm{C}$ and $126^{\circ} \mathrm{C}$, respectively.

The curing properties of the DGEBA/CMK-3 systems are characterized with the measurement of the conversion as a function of the temperature. The conversion is determined on the basis of the DSC thermograms with the following Eq. (1) [18]:

$$
\text { Conversion }\left(\alpha_{t}\right)=\frac{\Delta H_{t}}{\Delta H_{\text {Total }}} \times 100
$$

where $\alpha_{t}$ is the conversion at time (t), $\Delta H_{t}$ is the accumulated heat released before time $\mathrm{t}$, and $\Delta H_{\text {Total }}$ is the total heat released at the end of the reaction.

Fig. 2(b) shows the conversion as a function of the curing temperature for the DGEBA/CMK-3 systems obtained from the DSC thermograms. As shown in Fig. 2(b), it is clear that the conversions of DGEBA/CMK-3 systems move to high temperature with the addition of CMK-3. This is due to the pore volume that exists in CMK-3. The ring opening reaction of epoxides is delayed by the pore volume of the CMK-3 [19].

In this study, TGA thermograms are used to study the thermal information, i.e. the thermal stability and the thermal degradation behavior regarding CMK-3 content. Fig. 3 shows the thermal degradation (under nitrogen atmosphere) curves with a variety of CMK-3 content. And the thermal stability factors, i.e. the initial decomposition temperature (IDT, weight loss 5\%) and the temperature of the maximum rate of weight loss $\left(T_{\max }\right)$ of DGEBA/CMK-3 composites with a variety of CMK-3 content are summarized in Table 2.

As shown in Fig. 3 and Table 2, the thermal properties of
Table 2. Thermal Stability Factors and Thermal Conductivities of DGEBA/CMK-3 Composites

\begin{tabular}{ccccc}
\hline & IDT & $\mathrm{T}_{\max }$ & $\begin{array}{c}\mathrm{E}_{\mathrm{d}} \\
(\mathrm{kJ} / \mathrm{mol})\end{array}$ & $\begin{array}{c}\text { Thermal conductivity } \\
(\mathrm{W} /[\mathrm{m} \cdot \mathrm{k}])\end{array}$ \\
\hline Pure DGEBA & 378 & 430 & 255.8 & 0.33 \\
\hline $\begin{array}{c}\text { DGEBA/ } \\
\text { CMK-3 0.5 phr }\end{array}$ & 372 & 431 & 245.2 & 0.31 \\
\hline $\begin{array}{c}\text { DGEBA/ } \\
\text { CMK-3 1.0 phr }\end{array}$ & 372 & 429 & 239.2 & 0.24 \\
\hline
\end{tabular}

DGEBA: diglycidylether of bisphenol A, CMK-3: mesoporous carbon.

the DGEBA/CMK-3 composites with a variety of CMK-3 content showed a similar trend curve except for the final section with increasing temperature. Also, the rapid decomposition range of the internal structure presents itself at $400-450^{\circ} \mathrm{C}$ without regard to the $\mathrm{CMK}-3$ content.

From the TGA thermograms, the decomposition activation energy $\left(E_{t}\right)$ as a thermal stability factor was derived from Horowitz-Metzger, as follows in Eq. (2) [20]:

$$
\ln \left[\ln (1-a)^{-1}\right]=E_{t} q / R T_{s}^{2}
$$

where, $a$ is the decomposition fraction, $E_{t}$ the decomposition activation energy, $q$ the $T-T_{s}, T_{s}$ the temperature of the maximum decomposed rate, and $R$ the gas constant.

The decomposition activation energies $\left(E_{d}\right)$ for the pure DGEBA and the DGEBA/CMK-3 were determined from the slope of the $\ln \left[\ln (1-\alpha)^{-1}\right]$ vs. $\theta$ plots, as listed in Table 2. As shown in Table 2, the decomposition activation energy $\left(E_{d}\right)$ of the DGEBA/CMK-3 composites is lower than that of the pure DGEBA. This can be interpreted in terms of the slow thermal diffusion rate of the DGEBA/CMK-3, due to the pore volume that exists in CMK-3. Therefore, the crosslinking density of the DGEBA/ CMK-3 is lower than that of the pure DGEBA because the pore volumes in CMK-3 make the heat transfer for the curing reaction difficult.

The thermal conductivity of the cured specimens was measured by the Netzsch laser flash diffusivity system, LFA 447. The flash parameters used for this experiment were a laser voltage of $270 \mathrm{~V}$, and a $100 \%$ open filter. The thermal conductivities obtained from the Netzsch laser flash diffusivity system are listed in Table 2.

As shown in Table 2, the thermal conductivity is found to decrease with increase of the CMK-3 content. The low thermal conductivities of DGEBA/CMK-3 composites are a result of the thermal diffusion in the matrix resin being limited by the pore volume existing in the gaps on the interfaces between the mesoporous carbon and the DGEBA

\section{Conclusions}

The curing temperature and the main exothermic peaks 
moved to high temperature with the addition of the CMK-3. This was due to the facts that the ring opening reaction of epoxides was delayed by the pore volume in the CMK-3. The thermal stability factor, the $\mathrm{E}_{\mathrm{d}}$ value, was found to decrease with the addition of the CMK-3. However, there was not a significant difference in thermal stability properties.

The thermal conductivity was found to decrease with increase of the CMK-3 content. The low thermal conductivities of the DGEBA/CMK-3 composites were a result of the thermal diffusion in the matrix resin being limited by the pore volume existing in the gaps on the interfaces between the mesoporous carbon and the DGEBA.

From these experimental results, the thermal insulation property of DGEBA/CMK-3 composites can be improved by mixing of CMK-3 of a relatively low thermal conductivity.

\section{Acknowledgements}

This work was supported by the Honam Great-Sphere Economy Program.

\section{References}

[1] May CA. Epoxy Resins: Chemistry and Technology. 2nd ed., Marcel Dekker, New York (1988).

[2] Prolongo SG, Campo M, Gude MR, Chaos-Moran R, Urena
A. Compos Sci Technol, 69, 349 (2009).

[3] Heo GY, Park SJ. Macromol Res, 17, 870 (2009).

[4] Canto CF, De A. Prado LAS, Radovanovic E, Yoshida IVP. Polym Eng Sci, 48, 141 (2008).

[5] Seo MK, Choi KE, Park SH, Hong YT, Park SJ. Carbon Lett, 10, 329 (2009).

[6] Fesmire JE, Sass JP. Cryogenics, 48, 223 (2008).

[7] Khoun L, Hubert P. Polym Compos, 31, 1603 (2010).

[8] Sudo A, Isobe Y, Endo T. J Appl Polym Sci, 112, 836 (2009).

[9] Rosato DV, Di Mattia DP, Rosato DV. Designing with Plastics and Composites: A Handbook, Van Nostrand Reinhold, New York (1991).

[10] Lee ES, Lee SM, Shanefield DJ, Cannon WR. J Am Ceram Soc, 91, 1169 (2008).

[11] Kim KS, Choi KE, Park SJ. Carbon Lett, 10, 335 (2009).

[12] Kyotani T. Carbon, 38, 269 (2000).

[13] Hou Y, Guo L, Wang G. J Electroanal Chem, 617, 211 (2008).

[14] Baxter RI, Rawlings RD, Iwashita N, Sawada Y. Carbon, 38, 441 (2000).

[15] Bo X, Bai J, Wang L, Guo L. Talanta, 81, 339 (2010).

[16] Tan S, Zou W, Jiang F, Tan S, Liu Y, Yuan D. Mater Lett, 64, 2163 (2010).

[17] Sakamoto Y, Kaneda M, Terasaki O, Zhao DY, Kim JM, Stucky G, Shin HJ, Ryoo R. Nature, 408, 449 (2000).

[18] Waters DN, John LP. Anal Chem, 60, 53 (1988)

[19] Lin J, Wang X. Eur Polym J, 44, 1414 (2008).

[20] Jin FL, Park SJ. Polym Degrad Stab, 92, 509 (2007). 